ASTHMA

\title{
Asthma exacerbations in children immediately following stressful life events: a Cox's hierarchical regression
}

\author{
S Sandberg, S Järvenpää, A Penttinen, J Y Paton, D C McCann
}

\begin{abstract}
See end of article for authors' affiliations

.....................

Correspondence to: Dr S Sandberg,

Department of Mental

Health Sciences, University

College London, London

WIN 8AA, UK;

s.sandberg@ucl.ac.uk
\end{abstract}

Received 12 March 2004 Accepted

8 September 2004
Thorax 2004;59:1046-1051. doi: 10.1136/thx.2004.024604

Background: A recent prospective study of children with asthma employing a within subject, over time analysis using dynamic logistic regression showed that severely negative life events significantly increased the risk of an acute exacerbation during the subsequent 6 week period. The timing of the maximum risk depended on the degree of chronic psychosocial stress also present. A hierarchical Cox regression analysis was undertaken to examine whether there were any immediate effects of negative life events in children without a background of high chronic stress.

Methods: Sixty children with verified chronic asthma were followed prospectively for 18 months with continuous monitoring of asthma by daily symptom diaries and peak flow measurements, accompanied by repeated interview assessments of life events. The key outcome measures were asthma exacerbations and severely negative life events.

Results: An immediate effect evident within the first 2 days following a severely negative life event increased the risk of a new asthma attack by a factor of $4.69(p=0.00)$. In the period 3-10 days after a severe event there was no increased risk of an asthma attack $(p=0.5)$. In addition to the immediate effect, an increased risk of 1.81 was found $5-7$ weeks after a severe event $(p=0.002)$. This is consistent with earlier findings. There was a statistically significant variation due to unobserved factors in the incidence of asthma attacks between the children.

Conclusion: The use of statistical methods capable of investigating short time lags showed that stressful life events significantly increase the risk of a new asthma attack immediately after the event; a more delayed increase in risk was also evident 5-7 weeks later.
W hile the role of stress in the pathogenesis of childhood asthma still remains controversial, a growing body of research suggests that psychosocial stress is likely to be a factor contributing to the development of wheezing illnesses and asthma, especially during early childhood. ${ }^{1-3}$ High levels of psychosocial stress have also been shown to predict greater morbidity in children who already have asthma, ${ }^{4-6}$ and to correlate with poorer quality of life. $^{7}$

Three recent studies, ${ }^{8-10}$ one with children and two with adults, point to a time related association between exposure to stress and acute worsening of asthma symptoms among people who already have the disease.

A study involving college students ${ }^{8}$ with allergic asthma showed that, when challenged with antigen exposure at the time of stressful final examinations, a significant increase in eosinophilic airway inflammation was accompanied by a significant fall in forced expiratory volume in 1 second $\left(F_{1}\right) 24$ hours after the challenge. A second study examined the effect of experimentally induced stress under laboratory conditions in adults with asthma. ${ }^{9}$ There was a rapid and significant increase in respiratory symptoms and an increase in respiratory resistance immediately following exposure to stressful stimuli eliciting negative emotions.

The only study to examine the temporal relationship between major stress experiences and asthma in a prospective design involved children with asthma and showed that stressful life events increased the risk of a new asthma attack in the coming few weeks. ${ }^{10}$ The magnitude and timing of the maximum risk was determined by the presence or absence of chronic psychosocial stress. On their own, severely negative life events significantly increased the risk of an acute exacerbation over the subsequent 3-6 week period. If, in addition, the child was living under conditions of high chronic stress, the risk was further increased and brought forward in time. This study used a dynamic logistic regression analysis with time dependent blocks of 2 weeks. Although this analysis confirmed that there were time dependent effects of stress, because of the statistical approach used it was not possible to detect any more immediate effects of the stressful life events.

There also exist two earlier experimental studies involving children. $^{1112}$ In both of these stressful emotions were deliberately induced (asking the child to recall and describe most frightening and most anger provoking memory in the former, and by a stress inducing academic task in the latter). Both studies showed a significant decrease in $\mathrm{FEV}_{1}$ under conditions of emotional arousal verified by an increase in heart rate.

More recently, animal studies have shown that exogenous stress can affect airway function ${ }^{13}$ or airway inflammation in mice, ${ }^{14}$ and have started to dissect out the pathophysiological mechanisms that led to the changes observed. An important conclusion from this evidence is therefore that stress can cause a relatively rapid decrease in airway function.

A key feature of asthma is the fact that it is episodic. It is feasible to view consecutive asthma exacerbations as serial events resembling a repeated phenomenon. This, in turn, can be modelled statistically by survival analysis techniques. In the case of an individual subject, the time periods between individual asthma attacks can be assumed to be nearly independent of one another and to follow a distribution specific to the particular child. Methods of survival analysis can then be used to examine the effects of the factors (covariates) influencing the length of the intervening time periods. Survival analysis techniques may therefore provide more appropriate statistical approaches to investigating the immediate effects of stress on function or disease physiology. 
In the present study we have used a survival analysis approach (hierarchical Cox regression), using data previously collected in a prospective study of children with asthma, ${ }^{10}$ specifically to examine whether any immediate effect of stressful life events could be identified in children with asthma. We have focused on the impact of negative life events in children who were not living under conditions of high chronic stress. Of the 20 children with high chronic stress included in the previous analysis, only 12 would have been eligible for the present study-a number too small for meaningful comparisons.

\section{METHODS}

\section{Design of study}

The study was carried out as a prospective follow up over a period of 18 months. Separate teams, who were unaware of the other team's results throughout the study, independently assessed the asthma and life events.

\section{Subjects}

Of the total of 70 children without high chronic stress aged 6-13 years (mean 8.5 ) originally taking part in the study, 60 were included in the analyses. Ten were excluded either because they had no or only one asthma attack in the study period $(n=8)$, while two children had two attacks but substantial periods of missing data. These 10 children also by chance had very few life events.

The sample selection procedure and the assessment methods have been fully described previously, ${ }^{10}{ }^{15}$ so only a brief synopsis is included here. The children were regular attendees at a specialist asthma clinic at the Royal Hospital for Sick Children in Glasgow, Scotland from which recruitment took place, with the child's age being the only selection criterion. The male/female ratio was $52 \% / 48 \%$, with $62 \%$ being children of parents in professional/managerial occupations, $32 \%$ in skilled occupations, and $6 \%$ in semiskilled/ unskilled (including those on state benefits) occupations. ${ }^{16}$ The parental smoking ratio was $45 \% / 55 \%$ non-smokers/ smokers.

\section{Severity of asthma}

All the children had suffered from periodic asthma for a minimum of 3 years and from continuing medically diagnosed asthma in the year preceding the start of the study. All were taking prophylactic therapy with inhaled corticosteroids, together with intermittently or regularly administered bronchodilatators. The severity of asthma, rated on a 6-point scale from 1 to $5 \mathrm{~b}$ (based on the management steps defined by the British Thoracic Society ${ }^{17}$ ) according to prescribed medication over the previous year, was scored as 3 (mild to moderate) in 24 cases, 4 (moderate to severe) in 20, and 5 (severe; collapsing original categories $5 \mathrm{a}$ and $5 \mathrm{~b}$ because of small numbers) in 16 patients.

\section{Measurement of life events}

The Psychosocial Assessment of Childhood Experiences (PACE), ${ }^{15}{ }^{18}$ a standardised investigator based interview of proven reliability and validity, was used in every case to assess the timing of occurrence, nature and impact of discrete life events. There were no missing data on any aspect of the PACE assessments.

The PACE interview is conducted independently with the child and his/her main caregiver (the mother in all but one instance) using two parallel versions, one for children and one for parents. The following areas of the child's life are systematically covered: moves, changes in the household (births, people leaving/entering), separations from family, illnesses and hospital contacts, parents' work, family relationships, school, major traumatic incidents, and especially good happenings. The principal criteria for accepting something as a life event are that most children of the subject's age would find the incident either (a) threatening, upsetting, or unsettling, or (b) very pleasant, enhancing self-esteem or opening up new opportunities.

The information gathering and retrieval process took place in three stages:

Stage 1: As is usually the case with semi-structured interviewing, it is the job of the interviewer to decide when the incidents and experiences reported by the child or parent meet the requirements for inclusion as a "life event" or "long term experience". The criteria for defining life events and long term experiences are clearly set out in a manual, together with operational guidelines. Further information is elicited about the circumstances and details of the life event including the timing of its occurrence. A great deal of care and skill is required in helping the younger children, in particular, to achieve this. Specific techniques of using certain "anchor points" such as Christmas, family birthdays, or school starting dates are used to help the individual child to "order" and "time" their personal life experience material.

Stage 2: A synopsis of the child's circumstances is then presented to a trained colleague (panel) referring to an extensive dictionary of examples and, following discussion, contextual ratings are made for the degree of negative and positive (not used in this study) impact each event is judged to have had on the child. The impact on the day the event occurred and 10 days later is rated for "short term" and "long term" threat, respectively. The weighted kappas range from 0.87 to $0.93 .^{18}$

Stage 3: After the parent and child interviews have been separately processed and rated, a consensus meeting is held to combine them into a composite "best estimate" assessment of occurrence, timing, and impact (contextual threat). In the case of younger children, in particular, the timing is usually based on parent report.

Contextual threat refers to the level of threat caused or implied by the event to the child in question. Thus, contextual threat is simultaneously an objective and personalised measure. The existing evidence suggests that most of the risk associated with life events stems from their negative aspects. For this reason, the present study confined itself to severely negative life events (those carrying a high long term threat).

Measurement of chronic stress (long term experiences) The existence of a wide range of chronic life experiences was also determined-for example, prolonged separation, illness (the child's asthma excluded in the present study), and family breakdowns. Any such ongoing situations are rated for their type, timing, and objective impact. Of the individual types of negative long term experience, those to do with parenting difficulties, child's friendship difficulties, or being socially isolated, and the parents' marital problems are most often (4 out of 5 instances) regarded as having a high negative impact on the child. The majority of these (up to $80 \%$ ) last at least a year. ${ }^{15}$ The present analyses were based on children with low to moderate chronic stress (up to three highly negative long term experiences).

\section{Monitoring of asthma}

The children, often with the help of a parent, continuously monitored the course of their asthma by completing twice daily peak flow recordings and daily diaries reporting symptoms with planned clinic review every 3 months. Acute asthma exacerbation was defined as a documented fall in peak flow (the mean of the day's two readings) below $70 \%$ of the child's normal value combined with a documented increase in reported symptoms. 

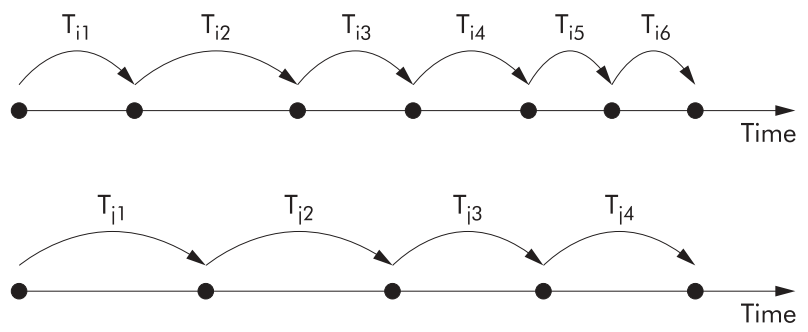

Consecutive intervals between asthma attacks for children i and i

Figure 1 Description of asthma attacks in terms of intervals.

\section{Missing asthma data}

Of the 60 children, 45 (75\%) had complete records of peak flow data between the first and the last asthma exacerbation while the remaining 15 (25\%) had some gaps in their diaries. The total number of intervals between consecutive asthma attacks in the returned diary booklets was 301; 30 of these $(10 \%)$ contained missing data. The total length of time with missing data per child varied from 13 to 339 days, with the individual periods with no recordings varying between 7 and 229 days. The intervals with missing peak flow recordings were excluded from the data analysis.

\section{Statistical methods}

The focus of the present analysis was on the immediate effects of severely negative life events on asthma exacerbations in children. In order to achieve this objective, a model based on the length of the time intervals between consecutive asthma attacks was adopted. It assumed that a series of successive asthma attacks in a particular child are a renewal phenomenon where, without any external intervention, the attack intervals are independent and identically distributed. ${ }^{19}$ This type of process is called a "renewal process" and is specific for each child (fig 1). The present data included observations of attack intervals for each child. It should be noted that a so called intraclass correlation exists in such data for the whole study group because the asthma level varied between the children.

The analysis of renewal interval data under independence assumption is within the frame of survival analysis where a Cox's proportional hazards model ${ }^{20}$ is a commonly used approach. Fixed effects such as sex, parental smoking, and baseline asthma severity (according to earlier assessment) are presumed to affect attack intervals and were used in the Cox regression as covariates. These effects are of interest as such and, in addition, reduce variation in the attack interval data. This model has the advantage of operating on a basic time unit of 1 day and hence allows better investigation of any effects of stress occurring soon after exposure.

Variation between children was modelled in the data in terms of individual level random components called frailties. These were assumed to be gamma-distributed. The role of the random component is to model the effect of unobserved factors in children such as asthma severity that potentially affect the incidence of asthma attacks. This led to a hierarchical Cox regression known as the frailty model. ${ }^{20}$

The main objective was to study more immediate effects of severely negative life events on asthma exacerbations or, in this case, on intervals between consecutive asthma attacks. This type of covariate differs from the previous ones by being time dependent. The crucial choice to be made here was to tailor the measurement to the model. Given the definition used in the interview schedule ${ }^{15}$ and the evidence highlighted above about the early effects of stress, it was assumed that a severely negative life event had a possible effect on the asthma interval for a minimum of 10 days. In order to capture any immediate effects, this interval was further divided into two consecutive intervals, 1-2 days and 310 days (that is, 2 and 8 days of length, corresponding approximately with the short and long term threat). This effect was additively modelled by means of two functions being indicators of the intervals $1-2$ and 3-10 days and having different regression coefficients. These functions were included in the basic hazard function. We called this effect an external (time dependent) covariate. Figure 2 illustrates the hierarchical model.

The computation was carried out using the function coxph, which can be obtained in the R-library survival.

\section{RESULTS}

\section{Number of severe life events and acute asthma} exacerbations

The mean (SD) length of observation time in the 60 children included in the study (date between the first and last recorded peak flow) was 633 (57) days (range 343-757), leaving out attacks on 18 children before or after the time range. ${ }^{10}$ These data are included in the present analysis with the time window for each child chosen to be from the first asthma attack to the last one. Altogether, 361 new asthma exacerbations occurred (mean number 6; mean duration 12.2 days), ranging from two (in seven children) to 23 (in one child). The number of severely negative life events was 124 with a mean (per child) of 2.1, ranging from 0 (in 19 children) to 9 (in one child).

\section{Risk of new asthma exacerbations following severe events}

The fixed effects included in the model were sex (boy $=0$, girl $=1)$, parental smoking $($ none $=0$, smoking $=1$ ), and the baseline level of asthma for which the two lowest grades ("mild to moderate" and "moderate to severe") were aggregated resulting in two categories of severity ( 0 for "not severe" (44 children) and 1 for "severe" ( 16 children)). Other potential covariates available in the data were socioeconomic status of the parent and season (a time dependent covariate), but the resulting subgroups (for example, four children in low socioeconomic group) were too small for analysis.

The final model included the three fixed effects and two time dependent covariates (time intervals of $1-2$ and 310 days after a severely negative life event). These life event

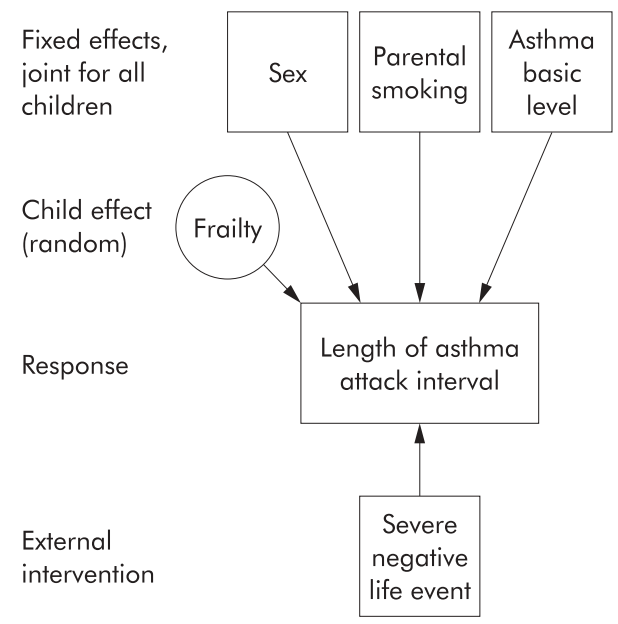

Figure 2 The hierarchical structure of the model. 


\begin{tabular}{|c|c|c|c|c|c|}
\hline Explanatory variables & $\begin{array}{l}\text { Multiplicative } \\
\text { change in } \\
\text { hazard }\end{array}$ & $95 \% \mathrm{Cl}$ & $\chi^{2}$ & df & $\mathrm{p}$ value \\
\hline \multicolumn{6}{|l|}{ Severe events } \\
\hline Effect in $1-2$ days after the event & 4.69 & 2.33 to 9.44 & 18.83 & 1.0 & 0.000014 \\
\hline Effect in 3-10 days after the event & 0.81 & 0.38 to 1.75 & 0.28 & 1.0 & 0.60 \\
\hline \multicolumn{6}{|l|}{ Fixed effects } \\
\hline Sex (girl $v$ boy) & 1.57 & 1.02 to 2.40 & 4.29 & 1.0 & 0.038 \\
\hline Parental smoking (yes $v$ no) & 1.13 & 0.71 to 1.79 & 0.27 & 1.0 & 0.60 \\
\hline Severity of asthma (serious $v$ not serious) & 1.71 & 1.07 to 2.72 & 5.05 & 1.0 & 0.03 \\
\hline Individual random component & & & 73.3 & 28.6 & 0.0000087 \\
\hline
\end{tabular}

covariates correspond to the classification suggested by previous evidence ${ }^{10}$ and preliminary data analysis.

The estimation results corresponding to this model are shown in table 1. Sex and the baseline asthma level had a statistically significant effect. For girls the risk of an asthma attack was 1.57 times higher than for boys. Children whose asthma was classified as severe had a 1.71 times higher risk than those with less severe asthma. Risk related to parental smoking was not statistically significant although it was larger than 1 (1.13).

The effect of a severely negative life event was as follows. The immediate effect corresponding to 1-2 days after the event increased the risk of a new asthma exacerbation by a factor of 4.69 which was statistically significant $(p=0.00)$, whereas the effect for days 3-10 after the event was not statistically significant $(p=0.5)$. The risk of an asthma attack varied considerably between children; the frailty term was highly significant $(\mathrm{p}=0.00)$.

It is of interest to compare how the results obtained by the frailty model based on the intervals between consecutive asthma attacks correspond to those ${ }^{10}$ derived from a dynamic logistic regression using a 14 day aggregation. Due to aggregation, the immediate effect observed using the present approach was not detectable. A further time dependent covariate-an indicator variable corresponding to the time interval starting 28 days (4 weeks) after the life event and lasting for 21 days ( 3 weeks) - was therefore added. The results of this analysis are shown in table 2 .

The life event increased the risk by a factor of 1.81 which is statistically significant $(\mathrm{p}=0.002)$. This is in accordance with

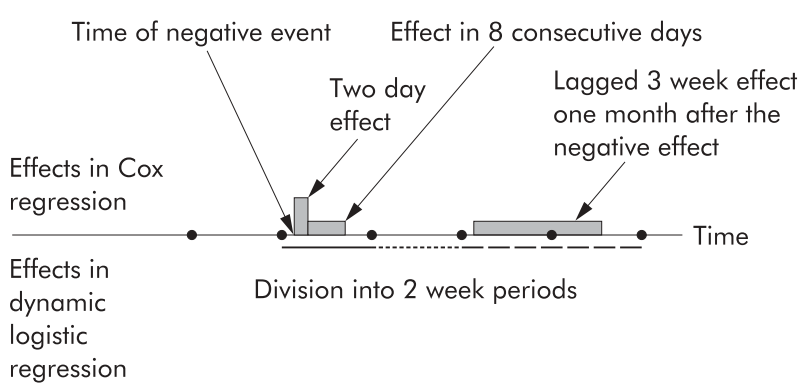

Figure 3 Comparison of the effects in the Cox regression model and the logistic dynamic regression model. ${ }^{10}$ In the latter model the first 2 week effect containing the negative effect cannot be detected (unbroken line), no effect was observed during the second 2 week period (dotted line), and a statistically significant lagged effect was observed during the following 4 week period (broken line).

the original findings. ${ }^{10}$ Note that the immediate effect was of the same magnitude as in the first model in this analysis.

\section{DISCUSSION}

In this study we have used the technique of survival analysis (Cox's hierarchical regression) on data previously collected in a prospective study ${ }^{10}$ specifically to examine whether any immediate impact of stressful life events could be identified in children with asthma who had no background of high chronic stress. The results were unequivocal: a rapid effect corresponding to $1-2$ days after a severely negative life event

\begin{tabular}{|c|c|c|c|c|c|}
\hline Explanatory variables & $\begin{array}{l}\text { Multiplicative } \\
\text { change in } \\
\text { hazard }\end{array}$ & $95 \% \mathrm{Cl}$ & $\chi^{2}$ & df & $p$ value \\
\hline \multicolumn{6}{|l|}{ Severe events } \\
\hline Effect 1-2 days after the event & 5.16 & 2.56 to 10.42 & 20.98 & 1.0 & 0.0000046 \\
\hline Effect 3-10 days after the event & 0.89 & 0.41 to 1.91 & 0.1 & 1.0 & \\
\hline $\begin{array}{l}\text { Delayed effect beginning } 28 \text { days after } \\
\text { the life event (duration } 21 \text { days) }\end{array}$ & 1.81 & 1.24 to 2.65 & 9.39 & 1.0 & 0.0022 \\
\hline \multicolumn{6}{|l|}{ Fixed effects } \\
\hline Sex (girl $v$ boy) & 1.58 & 1.03 to 2.42 & 4.37 & 1.0 & 0.037 \\
\hline Parental smoking (yes $v$ no) & 1.11 & 0.70 to 1.77 & 0.21 & 1.0 & 0.64 \\
\hline Severity of asthma (serious $v$ not serious) & 1.69 & 1.06 to 2.70 & 4.81 & 1.0 & 0.028 \\
\hline Individual random component & & & 75.42 & 28.9 & 0.0000049 \\
\hline
\end{tabular}


was noted. In this time the risk of a new asthma attack was increased nearly fivefold. After that time the risk was substantially reduced. However, the risk almost doubled again at 5-7 weeks after the severely negative life event. A statistical technique capable of examining the time-wise association between life events and asthma exacerbations in finer detail showed a rapid increase in the risk which was obscured by previous analyses employing dynamic regression using 2 week time periods. This analysis also confirmed the more delayed effect seen in the previous analysis. Figure 3 shows that the delayed effects obtained by the Cox regression model are consistent with those obtained by the dynamic regression model. ${ }^{10}$

One of the differences between the two models comes from modelling dependence. In the dynamic regression this was done by regression with the outcomes in the earlier time blocks. In the Cox regression model the difference is captured by a latent factor (frailty) for each child. The corresponding results show that, in the former case, an increased risk of an attack in the past predicts an increased risk in the near future and, in the latter case, the frailty is large.

The immediate and delayed effects of stressful life events on children's asthma exacerbations identified in this analysis are likely to be due to different underlying mechanisms. ${ }^{21}$ Previous research, however, offers only limited and somewhat inconsistent guidance for explaining the likely mechanisms. One reason for the seemingly contradictory findings and ensuing conclusions relates to the fact that the effects of stress have frequently been equated with those of emotional arousal. ${ }^{22}$ Although the two are often connected, they are far from equivalent. ${ }^{21}$ Only a few studies in children (or in adults) with asthma have so far examined the rapid effects of stress under experimental or laboratory conditions ${ }^{8911} 1223$ and, of these, all but one ${ }^{8}$ were probably measuring the effects of emotional arousal. Only animal studies ${ }^{13}$ have so far measured mediators of stress induced pathways such as neurohormones, neuropeptides, or markers of airway inflammation.

Complex neural mechanisms and alterations of the autonomic nervous system control the pathophysiology and symptomatology of asthma, ${ }^{624}$ with autonomic nerves impacting on airway calibre and function via effects on smooth muscle, bronchial vessels, and mucous glands. Hormones and neuropeptides released into the circulation when individuals experience stress are assumed to regulate inflammatory and airway responses. Conversely, many of the same autonomic mechanisms thought to have a role in asthma are involved in the activation and regulation of physiological responses to stress. In recent times the pivotal role of cytokines in coordinating the events of airway inflammation has been highlighted. ${ }^{25}$

Clinical and experimental studies suggest that stress and states of emotional arousal produce increases in airway resistance and can thus act as potential precursors of asthmatic symptoms. ${ }^{24}{ }^{26}$ Most of the research has focused on negative emotional states such as anger, sadness and depression, linking these to symptom aggravation. ${ }^{11}{ }^{12} 2^{22-24}$ It has also been suggested that increases in airway resistance are more readily explainable when stressful situations are unavoidable or inescapable, and therefore demand a passive coping response. ${ }^{27} \mathrm{~A}$ non-reciprocal pattern of autonomic functioning has been put forward as the underlying physiological mechanism. ${ }^{9}$ This is because, in some stressful situations, both vagally mediated bronchial constriction and extrabronchial sympathetic activity appear to increase in parallel. The relative strength of sympathetic versus parasympathetic control in response to certain forms of stress differs among individuals, with some showing a predominantly parasympathetic response. Such individuals may be particularly susceptible to stress induced bronchoconstriction. ${ }^{6}{ }^{26}$

Sympathetic activation itself might also contribute to asthma symptoms. It is, for example, known that increases in circulating levels of adrenaline and noradrenaline alter immune parameters causing the airways to become more susceptible to inflammation. The results of a recent experimental study ${ }^{8}$ appear to support this.

The more delayed effects of stress are perhaps more difficult to explain at present. It may be that, in the presence of chronic/repeated stress, the physiological response to acute stressors results in more sustained effects on the immune system, even following sympathetic recovery. Stress induced alterations in the immune response implicated in asthma ${ }^{25}$ could therefore explain the delayed effect seen in the present study.

Lower cortisol levels found in children with asthma ${ }^{28}$ may also be responsible for the lack of suppression of airway inflammation. It is possible that children with asthma experiencing high levels of repeated stress have lower cortisol levels and/or flatter cortisol rhythms indicating a less active HPA system to control inflammation processes related to asthma. ${ }^{25}$ This could serve as a further explanation for the delayed effect of stressful life events on asthma attacks found in this sample.

Forsythe et $a l^{14}$ have recently found both short and long term effects in experimental studies of differing durations of stress in mice. Repeated exposure to stress over the long term engaged different mechanisms than short term stress. In the short term, the anti-inflammatory effects of corticosterone were apparent leading to a decrease in inflammatory cells in lavage fluid. In the longer term, cell influx was exacerbated, an effect that did not appear to be mediated by the effects of corticosterone. Our present analysis may be the first evidence that similar short and long term effects can be observed in humans.

This report highlights a number of points that will be important for future clinical studies of the relationship between stress and asthma. Firstly, there is a need for prospective studies of sufficient size and duration to allow more detailed investigation of both the short term effects of stress on asthma and airway function, evident within days, and the longer term effects evident weeks to months later. Such studies should be analysed using statistical techniques that can allow detailed investigation of the time course of measured outcomes. Future studies will also need to distinguish between stimuli or events that cause stress and those more likely to be temporarily increasing physiological arousal, and to consider factors such as duration of the stress and levels of chronic adversity.

\section{ACKNOWLEDGEMENTS}

The authors thank the children and their parents for their generous cooperation in the study, Dr Clive R Hillary for his valuable contribution during the data gathering stage, and $\mathrm{Mr}$ David McGuinness for his statistical expertise throughout the study.

\section{Authors' affiliations \\ S Sandberg, Department of Mental Health Sciences, Royal Free and University College London Medical School, London, UK \\ S Järvenpää, A Penttinen, Department of Mathematics and Statistics, University of Jyväskylä, Jyväskylä, Finland \\ J Y Paton, Division of Developmental Medicine, University of Glasgow, Glasgow, UK \\ D C McCann, School of Psychology, University of Southampton, Southampton, UK}

This study was supported by the Medical Research Council, UK Igrant G9102413N), the Academy of Finland (grant 41224), and Laboratory of Data Analysis, Center for Mathematical and Computational Modelling, University of Jyväskylä, Finland. 


\section{REFERENCES}

1 Busse WE, Kiecolt-Glaser JK, Coe C, et al. Stress and asthma: NHLB workshop summary. Am J Respir Crit Care Med 1994;151:249-52.

2 Mrazek DA, Klinnert M, Mrazek PJ, et al. Prediction of early-onset asthma in genetically at-risk children. Pediatr Pulmonol 1999;27:85-94.

3 Wright RJ, Cohen S, Carey V, et al. Parental stress as a predictor of wheezing in infancy. A prospective birth-cohort study. Am J Respir Crit Care Med 2002; 165:358-65.

4 Randolph C, Fraser B. Stressors and concerns in teen asthma. Curr Probl Pediatr 1999;29:82-93.

5 Wade S, Weil C, Holden G, et al. Psychosocial characteristics of inner-city children with asthma: a description of the NCICAS psychosocial protocol: National Cooperative Inner-City Asthma Study. Pediatr Pulmonol 1997;24:263-76

6 Wright RJ, Rodriguez M, Cohen S. Review of psychosocial stress and asthma: an integrated biopsychosocial approach. Thorax 1998;53:1066-74.

7 Mishoe SC, Baker RR, Poole S, et al. Development of an instrument to assess stress levels and quality of life in children with asthma. J Asthma 1998;35:553-63.

8 Liu LY, Coe CL, Swenson CA, et al. School examinations enhance airway inflammation to antigen challenge. Am J Respir Crit Care Med 2002;165:1062-7.

9 Ritz T, Steptoe A, DeWilde S, et al. Emotions and stress increase respiratory resistance in asthma. Psychosom Med 2000;62:401-12.

10 Sandberg S, Paton JY, Ahola S, et al. The role of acute and chronic stress in asthma attacks in children. Lancet 2000;356:982-7.

11 Tal A, Miklich DR. Emotionally induced decreases in pulmonary flow rates in asthmatic children. Psychosom Med 1976;38:190-200.

12 Florin I, Freudenberg G, Hollaender J. Facial expressions of emotion and physiologic reactions in children with bronchial asthma. Psychosom Med 1985:47:382-94.

13 Joachim RA, Quarcoo D, Arck PC, et al. Stress enhances airway reactivity and airway inflammation in an animal model of allergic bronchial asthma. Psychosom Med 2003;65:811-5.

14 Forsythe P, Ebeling C, Gordon JR, et al. Opposing effects of short- and longterm stress on airway inflammation. Am J Respir Crit Care Med 2004; 169:220-6.
15 Sandberg S, Rutter M, Giles S, et al. Assessment of psychosocial experiences in childhood: methodological issues and some substantive findings. J Child Psychol Psychiatry 1993;34:879-97.

16 Office of Population Censuses and Surveys. Classification of occupations. London: HM Stationery Office, 1980.

17 British Thoracic Society. Guidelines on the management of asthma in children. Thorax 1993;48(Suppl): 1-24.

18 Glen S, Simpson A, Drinnan D, et al. Testing the reliability of a new measure of life events and experiences in childhood: the Psychosocial Assessment of Childhood Experiences (PACE). Eur Child Adolesc Psychiatry 1993;2:98-110.

19 Cox DR, Isham V. Point processes. London: Chapman \& Hall, 1980.

20 Therneau TM, Grambsch PM. Modelling survival data, extending the Cox model. New York: Springer-Verlag, 2000.

21 Klinnert MD. Evaluating the effects of stress on asthma: a paradoxical challenge. Eur Respir J 2003;22:574-5.

22 Rietveld S, Everaerd W, Creer TL. Stress-induced asthma: a review of research and potential mechanisms. Clin Exp Allergy 2000;30:1058-66.

23 Laube BL, Curbow BA, Fitzgerald ST, et al. Early pulmonary response to allergen is attenuated during acute emotional stress in females with asthma. Eur Respir J 2003;22:613-8.

24 Ritz T, George C, Dahme B. Respiratory resistance during emotional stimulation: evidence for a non-specific effect of experienced arousal? Biol Psychol 2000;52:143-60.

25 Chen E, Fisher EB, Bacharier LB, et al. Socioeconomic status, stress, and immune markers in adolescents with asthma. Psychosom Med 2003;65:984-92

26 Lehrer PM, Isenberg S, Hochron SM. Asthma and emotion: a review. J Asthma 1993;30:5-21.

27 Lehrer PM, Hochron S, Carr R, et al. Behavioral task-induced bronchodilatation in asthma during active and passive tasks: a possible cholinergic link to psychologically induced airway changes. Psychosom Med 1996;58:413-22.

28 Landstra AM, Postma DS, Boezen HM, et al. Role of serum cortisol levels in children with asthma. Am J Respir Crit Care Med 2002; 165:708-12.

\section{LUNG ALERT}

The eosinophil in airway remodelling and hyperresponsiveness in asthma: participant or bystander?

$\Delta$ Lee JJ, Dimina D, Macias MP, et al. Defining a link with asthma in mice congenitally deficient in eosinophils. Science 2004;305:1773-6

A Humbles AA, Lloyd CM, McMillan SJ, et al. A critical role for eosinophils in allergic airways remodelling. Science 2004;305:1776-9

W

hile the presence of eosinophils in asthma has long been recognised, it remains unclear whether they are directly involved in the pathogenesis of asthma or are merely an epiphenomenon. Both Lee et al and Humbles et al used an acute inhaled allergen challenge with ovalbumin as a model of asthma. Lee et al used mice that expressed diphtheria toxin A in eosinophils (PHIL mice) resulting in eosinophil apoptosis while Humble et al used mice with mutations in a transcription factor (GATA-1 mice) that selectively prevented the differentiation of myeloid cells into eosinophils. Both mutants were essentially devoid of eosinophils with preservation of other leucocytes.

Compared with wild type mice, the PHIL mice had reduced epithelial hypertrophy and goblet cell metaplasia while the GATA-l mice had decreased airway smooth muscle proliferation and fibrin deposition. This suggests that eosinophils have an important role in airway remodelling.

The PHIL mice were completely protected from developing airway hyperresponsiveness following allergen challenge, suggesting a key role for eosinophils, while the GATA-I mice had enhanced airway hyperresponsiveness following allergen challenge which suggests that eosinophils were not essential. The difference in response may have been due to the fact that the mice were developed from different background strains. Asthma is a multigenic disease and the importance of eosinophils in the pathogenesis of asthma may vary depending on the rest of the subject's genetic makeup. This could have important therapeutic implications. Targeted suppression of eosinophils may help to attenuate airway remodelling, but may only affect airway hyperresponsiveness in some asthma patients with the right genetic background. 


\section{PostScript}

\section{LETTERS TO THE EDITOR}

\section{Surgery in early NSCLC and co- morbidity}

We would like to congratulate JanssenHeijnen $e t ~ a l^{1}$ on their well performed study and on their significant contribution to resolving the problem of treatment in patients with non-small cell lung cancer (NSCLC) and co-morbidity. However, we could not find a description of the surgical approach used and would like to ask the authors to provide details of the surgical procedures adopted and the accompanying survival rates. We think, ${ }^{2}$ in agreement with other authors ${ }^{3}$ that, for patients with early stage NSCLC and co-morbidity, a less invasive surgical approach should be used. This view is supported by studies in elderly patients or in patients with co-morbidity showing that a less invasive approach does not influence survival rates. Only the recurrence rate seems to be increased by a less invasive surgical approach such as segmentectomy or pulmonary wedge resection. ${ }^{3-5}$

Several factors determine whether conservative or invasive resection should be used for NSCLC. We think that a less invasive approach should be chosen as the first therapeutic step, even for early stage NSCLC, and that elderly patients should be treated less aggressively than younger patients.

D Sortini, E Pozza, K Maravegias, A Liboni,

A Sortini

Section of General Surgery, Department of Surgical, Anaesthesiological and Radiological Sciences, University of Ferrara, Ferrara, Italy

Correspondence to: Dr D Sortini, Sezione di Chirurgia Generale, Dipartimento di Scienze Chirurgiche

Anestesiologiche e Radiologiche, Università di Ferrara, 44100 Ferrara, Italy; sors@libero.it

\section{References}

1 Janssen-Heijnen MLG, Smulders S, Lemmens VEPP, et al. Effect of comorbidity on the treatment and prognosis of elderly patients with non-small cell lung cancer. Thorax 2004; 59:602-7.

2 Sortini D, Feo C, Carcoforo P, et al. Thoracoscopic localization techniques for patients with solitary pulmonary nodule and history of malignancy. Ann Thorac Surg 2005;79:258-62.

3 Sugarbaker DJ. Lung cancer. 6: The case for limited surgical resection in non-small cell lung cancer, Thorax 2003;58:639-41.

4 Kodama K, Doi O, Higashiyama $M$, et al. Intentional limited resection for selected patients with T1 NO MO non-small-cell lung cancer: a single-institution study. J Thorac Cardiovasc Surg 1997; 114:347-53.

5 Landreneau RJ, Sugarbaker DJ, Mack MJ, et al. Wedge resection versus lobectomy for stage I (T) NO MO) non-small-cell lung cancer. J Thorac Cardiovasc Surg 1997;113:691-8.

\section{Authors' reply}

We agree with Sortini and colleagues that the type of surgical procedure may influence survival. Several studies have shown that less invasive resections might be a good
If you have a burning desire to respond to a paper published in Thorax, why not make use of our "rapid response" option?

Log onto our website (www.thoraxjnl. com), find the paper that interests you, and send your response via email by clicking on the "eletters" option in the box at the top right hand corner.

Providing it isn't libellous or obscene, it will be posted within seven days. You can retrieve it by clicking on "read eletters" on our homepage.

The editors will decide as before whether to also publish it in a future paper issue.

alternative for the elderly and those with co-morbidity because postoperative mortality and complications are rather high in these patients. ${ }^{1-5}$ We did not present survival rates for the different surgical approaches because the numbers of patients in the subgroups were rather small, especially for the less invasive resections like sleeve resection, segmentectomy, and wedge resection. However, at the request of Sortini and colleagues, we here present the results for the different surgical approaches.

Figure 1 shows the proportional distribution of surgical approaches in resected patients with stage I and II NSCLC according to age and number of co-morbid conditions. Elderly patients received a pneumonectomy less often, while the proportion of lobectomies and less invasive resections increased with age. In age groups $<60$ years and 70 79 years patients with co-morbidity received pneumonectomy less often and a lobectomy/ less invasive resections more often than those without co-morbidity. In patients older than 80 years the number of patients was too small to draw any conclusions.

In the multivariate survival analysis of resected stage I and II NSCLC patients, those treated with bilobectomy $(\mathrm{HR}=0.70, \mathrm{p}=$ $0.08)$ or lobectomy $(\mathrm{HR}=0.70, \mathrm{p}=0.003)$ had a significantly better survival than those treated with pneumonectomy, adjusted for age, sex, tumour size, histological subtype, and co-morbidity. Survival in patients treated with less invasive resections was not significantly different. The absence of a difference might be explained by the small number of patients in this subgroup $(n=47)$.

We want to emphasise that this is an observational population based study and not a randomised controlled trial. Among the elderly, probably only the fittest patients were selected for surgery. Although we adjusted for the above mentioned patient related and tumour related factors in the multivariate survival analysis, other selection factors for surgery such as performance status, ASA score, forced expiratory volume in 1 second, and patient's choice might have confounded the results.

Since the recurrence rate has been shown to be higher in patients who underwent less invasive surgery (such as wedge resection), lobectomy or pneumonectomy remain the surgical approaches of first choice in patients who are fit enough to undergo invasive surgery. ${ }^{4}$ Since it is still not clear what assessment is necessary in order to assess whether an older patient is fit enough for

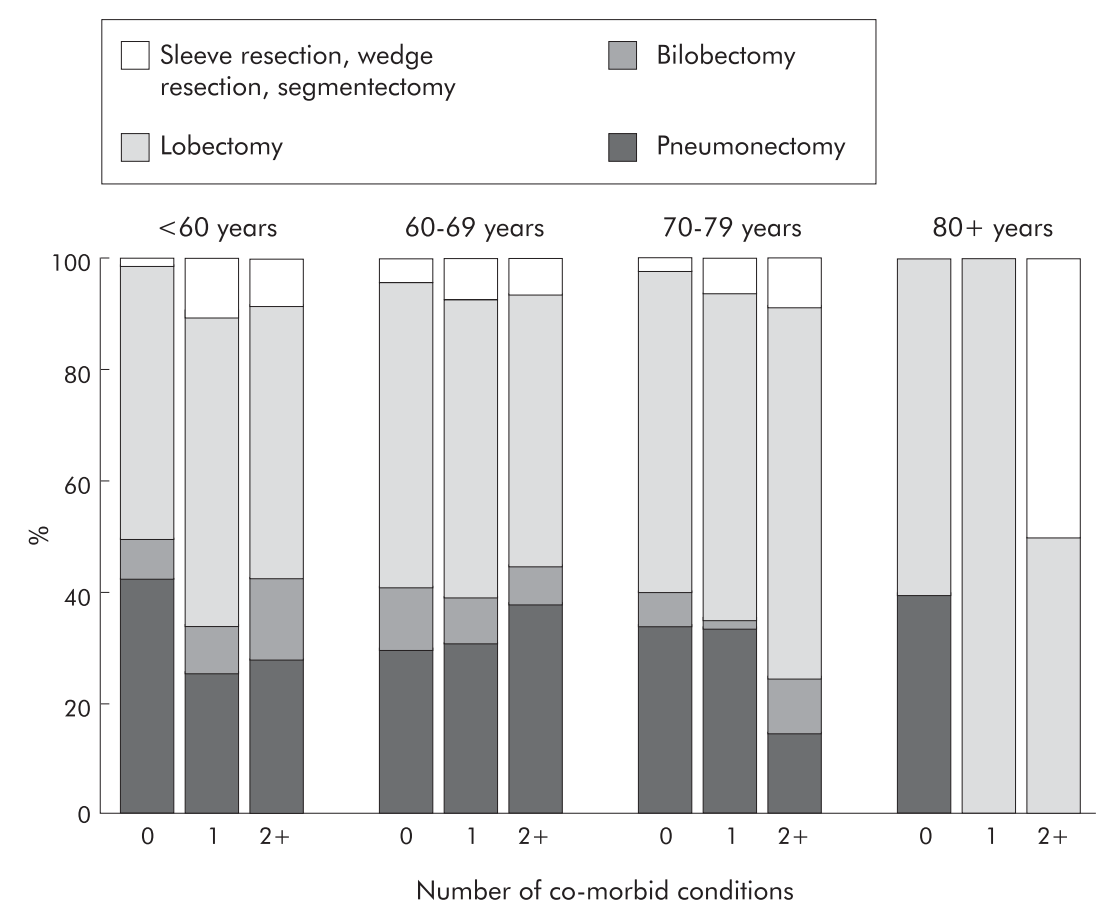

Figure 1 Surgical approach for surgically resected localised NSCLC according to age and comorbidity. 
invasive surgery, future studies should focus on this topic.

M L G Janssen-Heijnen, H J A A van Geffen, V E P P Lemmens, F W J M Smeenk, S A Smulders, J W W Coebergh Eindhoven Cancer Registry, The Netherlands

Correspondence to: $\operatorname{Dr} M L G$ Janssen-Heijnen, P O Box 231, 5600 AE Eindhoven, The Netherlands; research@ikz.n

\section{References}

1 Harvey JC, Erdman C, Pisch J, et al. Surgical treatment of non-small cell lung cancer in patients older than seventy years. J Surg Oncol 1995;60:247-9

2 Kodama K, Doi O, Higashiyama $M$, et al. Intentional limited resection for selected patients with T1 NO MO non-small-cell lung cancer: a single-institution study. J Thorac Cardiovasc Surg 1997; 114:347-53.

3 Landreneau RJ, Sugarbaker DJ, Mack MJ, et al. Wedge resection versus lobectomy for stage I (T) NO MO) non-small-cell lung cancer. J Thorac Cardiovasc Surg 1997;113:691-8, discussion 698-700.

4 Sugarbaker DJ. Lung cancer. 6: The case for limited surgical resection in non-small cell lung cancer, Thorax 2003;58:639-41.

5 Alexiou C, Beggs D, Onyeaka P, et al. Pneumonectomy for stage I (T1NO and T2NO) nonsmall cell lung cancer has potent, adverse impact on survival. Ann Thorac Surg 2003;76: 1023-8.

\section{Recruitment of ethnic minorities to asthma studies}

The research letter by Sheikh and co-authors addresses an important area but, regrettably, does not hit the nail on the head. Information on ethnicity of study participants is often missing in asthma studies, as the authors clearly show. However, presenting this information-for example, in the table of baseline characteristics when reporting a clinical trial-is only a first step. Much more important is the inclusion of this characteristic in the analysis of effect modification or subgroup analysis. Only then will we know whether ethnicity really matters when applying a certain intervention.

I would welcome a further report from the authors giving details about the actual incorporation of ethnicity in data analysis.

J C van der Wouden

Department of General Practice, Erasmus MC University Medical Center Rotterdam, P O Box 1738 3000 DR Rotterdam, The Netherlands i.vanderwouden@erasmusmc.nl

\section{Reference}

1 Sheikh A, Panesar SS, Lasserson T, et al. Recruitment of ethnic minorities to asthma studies. Thorax 2004;59:634.

\section{Authors' reply}

We are grateful to Dr van der Wouden for raising the important point of ensuring that ethnicity data are used when analysing trial results. Of the $23 / 70$ studies $(32.8 \%)$ reporting information on ethnicity in the trial report, all confined mention of ethnicity only to baseline characteristics of included participants. Thus, none of these 23 studies factored ethnicity into the analysis of results A possible explanation for this rather disappointing observation is that the number of subjects recruited from minority ethnic groups tended to be small, thereby precluding any meaningful ethnic-specific subgroup analysis. Unfortunately, this is a problem not solely confined to asthma studies; for example, less than $30 \%$ of clinical trials on epilepsy which reported ethnicity used the information in the analysis. ${ }^{1}$

In designing clinical trials, pragmatic and cost considerations often force investigators to focus on the main objectives of the study, forcing considerations concerning subgroup analyses onto the back burner during trial planning. Most clinical trials therefore lack sufficient power for subgroup analyses; ${ }^{2}$ however, this appears to be a problem that is particularly common in relation to subgroup analysis by ethnicity. ${ }^{3}$

Our motivation for undertaking this study was to highlight the disparity in recruitment between ethnic minorities and the majority into trials in a disease where ethnic considerations may be relevant. Asthma is one such area, but there are also others. ${ }^{4}$ van der Wouden is entirely correct in asserting that improving recruitment of minority ethnic groups is only half the battle; at least equally important-if not more so-is ensuring that information on ethnicity is meaningfully and competently used when analysing data and presenting results. ${ }^{5}$ Both issues should now be prioritised by the respiratory research community.

G Netuveli, S S Panesar

Division of Primary Care and Population Health Sciences, Imperial College, London, UK

T Lasserson

Cochrane Airways Group, St George's Hospital Medical School, London, UK

A Sheikh

Department of Primary Care Research and Development, Division of Community Health Sciences: GP Section, University of Edinburgh, UK

Correspondence to: Professor A Sheikh, Department of Primary Care Research and Development, Division of Community Health Sciences: GP Section, University of Edinburgh, UK; aziz.sheikh@ed.ac.uk

\section{References}

1 Burneo JG, Martin R. Reporting race/ethnicity in epilepsy clinical trials. Epilepsy Behav 2004;5:743-5.

2 Pocock SJ, Assmann SE, Enos LE, et al. Subgroup analysis, covariate adjustment and baseline comparisons in clinical trial reporting: current practice and problems. Stat Med 2002;21:2917-30.

3 Svensson CK. Representation of American blacks in clinical trials of new drugs. JAMA 1989;261:263-5.

4 Gifford AL, Cunningham WE, Heslin KC, et al. Participation in research and access to experimental treatments by HIV-infected patients. N Engl J Med 2002;346:1373-82.

5 Schwartz RS. Racial profiling in medical research. N Engl J Med 2001;344:1392-3

\section{$E B C \mathrm{pH}$ and chronic cough}

We read with interest the recent article by Niimi et al reporting low levels of exhaled breath condensate (EBC) $\mathrm{pH}$ in patients with chronic cough. ${ }^{1}$ We and others have described low EBC $\mathrm{pH}$ in association with airway inflammation in allergic asthma, cystic fibrosis, and chronic obstructive pulmonary disease. $^{2-4}$ In these studies there is a relatively close association between inflammation and low $\mathrm{pH}$ which is shown by the further fall in $\mathrm{pH}$ during exacerbations. ${ }^{2}$ However, in non-asthmatic chronic cough, while there is a low grade inflammation present in some subjects, this is much less than would be required to invoke inflammation as the major cause of airway acidification.

It is unclear from the description of the assessment protocol how patients were allotted their individual diagnostic categories. A positive methacholine challenge test is not infrequently found in patients with reflux ${ }^{5}$ and, even in classical asthma, reflux is a common phenomenon. ${ }^{6}$ We would suggest that there has been a significant underdiagnosis of reflux disease in this cohort because of the lack of a structured history, the non-uniform application of investigations, and the failure to perform full oesophageal assessment, particularly manometry. We have shown that, when oesophageal manometry is not performed, a significant number of patients with reflux cough will be missed. ${ }^{7}$ Proton pump inhibitors at conventional doses only temporarily increase the $\mathrm{pH}$ of gastric reflux and do not prevent reflux per se and, unsurprisingly, only improve symptoms in a proportion of patients with reflux cough. A failure of cough to improve with proton pump inhibitors does not therefore adequately rule out reflux cough.

The simplest explanation for the low airway $\mathrm{pH}$ observed by Niimi et al is that a large proportion of the subjects had laryngopharyngeal reflux. This would also explain the otherwise surprising finding of a similar EBC pH across the authors' diagnostic categories.

A Morice

Academic Department of Medicine, Castle Hill Hospital, Cottingham, East Yorkshire HU16 5JQ, UK; a.h.morice@hull.ac.uk

\section{References}

1 Niimi A, Nguyen LT, Usmani O, et al. Reduced pH and chloride levels in exhaled breath condensate of patients with chronic cough. Thorax 2004;59:608-12.

2 Ojoo JC, Mulrennan S, Kastelik JA, et al. Exhaled breath condensate $\mathrm{pH}$ and exhaled nitric oxide in allergic asthma and in cystic fibrosis. Thorax 2005;60:22-6.

3 Kostikas K, Papatheodorou G, Ganas K, et al. pH in expired breath condensate of patients with inflammatory airway diseases. Am J Respir Crit Care Med 2002:165:1364-70.

4 Tate S, MacGregor G, Davis M, et al. Airways in cystic fibrosis are acidified: detection by exhaled breath condensate. Thorax 2002;57:926-9.

5 Bagnato GF, Gulli S, Giacobbe O, et al. Bronchial hyperresponsiveness in subjects with gastroesophageal reflux. Respiration 2000;67:507-9

6 Vincent D, AM, Leport J, et al. Gastrooesophageal reflux prevalence and relationship with bronchial reactivity in asthma. Eur Respir $J$ 1997; 10:2255-9.

7 Kastelik JA, Redington AE, Aziz I, et al. Abnormal oesophageal motility in patients with chronic cough. Thorax 2003;58:699-702.

\section{Effect of oxygen on recovery from maximal exercise in COPD}

I read with great interest the article by Stevenson and Calverley and related editorial. ${ }^{12}$ An important and unexplained finding was the fact that instrumented patients using a mouthpiece and noseclip took significantly longer to recover from breathlessness after exercise than those who wore only a facemask (non-instrumented), irrespective of oxygen or air delivery. The mean (SE) 
difference was 3.94 (1.77) minutes in a total exercise recovery period of 11.38 (1.49) minutes for fully instrumented patients. Various theories to explain this exceptional difference have been offered both by the authors and reviewer. These have mainly centred on the theme of inhibition of ventilation from the persistence of primitive diving reflexes.. However, the precise mode of ventilation of these patients in the recovery phase via the mouth or nose needs consideration.

We have recently reported that normal subjects have both quantitative and qualitative differences in ventilation and ventilatory patterns when adopting nasal compared with oral routes for ventilation. ${ }^{45}$ Minute ventilation and its components (tidal volume and breathing frequency) were reduced by a mean of $33 \%$ and followed a shift of thoracoabdominal respiration to favour "diaphragmatic" breathing during nasal ventilation and "upper thoracic cage" during mouth breathing. The clinical implications of this have been explored by using a specifically designed questionnaire to discover breathing preferences (mouth/nose) in patients with chronic respiratory diseases including COPD. The findings revealed a high prevalence of symptoms of dysfunctional ventilation and, for the first time, strongly linked them to a preference for mouth breathing. ${ }^{6}{ }^{7}$

Evidence now suggests that proprioceptive input from a number of sources (including pulmonary and chest wall) forms the final common pathway for the perception of breathlessness. ${ }^{8}$ Thus, it seems that mouth breathing per se may predispose to the perception of breathlessness by dynamically changing chest wall mechanics by a resultant increase in ventilation and subtle shift in thoracoabdominal respiration.

Fully instrumented patients in the study are, by definition, obligate mouth breathers and, for the reasons offered, this may provide the sole explanation for the findings of the persistent breathlessness. The relevance of the time honoured practice of measuring ventilation with a mouthpiece and noseclip needs to be carefully reviewed in the future.

A J Williams

Department of Thoracic Medicine, Royal Bournemouth Hospital, Bournemouth BH7 7DW, UK; Alan. Williams @rbch-tr.swest.nhs.uk

\section{References}

1 Stevenson NJ, Calverley PMA. Effect of oxygen on recovery from maximal exercise in patients with chronic obstructive pulmonary disease. Thorax 2004:59:668-72.

2 Roberts CM. Short burst oxygen therapy for the relief of breathlessness in COPD. Thorax 2004;59:638-40.

3 Folgering $\mathrm{H}$, Olivier $\mathrm{O}$. The diving response depresses ventilation in man. Bull Eur Physiopathol Respir 1985;21:143-7.

4 Brammer PA, Compton-Price T, Williams AJ. Changes in ventilatory patterns and lung volumes during oral and nasal breathing in normal subjects. Am J Respir Crit Care Med 2001; 163:A413.

5 Williams AJ, Compton-Price T. Quantitative and qualitative differences in lung function and ventilatory patterns in normal subjects adopting oral and nasal breathing. Am J Respir Crit Care Med 2003; 167:A545

6 Williams AJ, Speed K, Compton-Price T. Mouth breathing and ventilatory dysfunction in respiratory disease - a new perspective. Am J Respir Crit Care Med 2004; 169:A724.

7 Williams AJ, Speed K, Compton-Price T. Interrelationships between mouth breathing and ventilatory dysfunction in respiratory disease. Thorax 2003;58(Suppl III):iii71.

8 Killian KJ, Campbell EJM. Dyspnoea. In: Roussos C, Macklem PT, eds. The thorax. Part B. 2nd ed. New York: Marcel Decker, 1985: 1709-47.

\section{Authors' reply}

We are grateful for Dr Williams' positive comments about our study which was primarily designed to evaluate the relationship between the physiological effects of supplementary oxygen in normoxaemic COPD patients and the intensity of their dyspnoea when oxygen was administered after a standardised exercise stimulus. ${ }^{1}$ The difference between the instrumented and noninstrumented patients was not a primary outcome and should therefore be interpreted with some caution, at least from the statistical point of view. Nonetheless, we agree that stimulation of upper airway receptors can be an important mechanism for modifying respiratory sensation, as we suggested several years ago when we found that administering cold air during exercise reduced the intensity of exercise induced dyspnoea. ${ }^{2}$ We can confirm that breathing with a noseclip and mouthpiece modifies the pattern of regional chest wall ventilation in COPD patients compared with non-instrumented breathing when assessed by optoelectronic plethysmography. These changes at rest did not modify the pattern of chest wall movement during exercise that we recently described ${ }^{3}$ and this would argue against Dr Williams' suggestion that the breathing route is a major contributory factor to dyspnoea intensity. It is possible that the switch to mouth breathing reflects a need to reduce inspiratory resistance and is thus an adaptive response in these patients. Further work in this interesting area will be needed to resolve these important issues.

P M A Calverley

University Hospital Aintree, Liverpool, UK; pmacal@liverpool.ac.uk

\section{References}

1 Stevenson NJ, Calverley PM. Effect of oxygen on recovery from maximal exercise in patients with chronic obstructive pulmonary disease. Thorax 2004;59:668-72.

2 Spence DP, Graham DR, Ahmed J, et al. Does cold air affect exercise capacity and dyspnea in stable chronic obstructive pulmonary disease? Chest 1993;103:693-6.

3 Aliverti A, Stevenson N, Dellaca RL, et al. Regional chest wall volumes during exercise in chronic obstructive pulmonary disease. Thorax 2004;59:210-6

\section{$\alpha_{1}$-Antitrypsin genotype unaffected by age}

In a recent otherwise excellent editorial in Thorax, ${ }^{1}$ Dr Seersholm indicated that our previous results on the decline in forced expiratory volume in l second $\left(\mathrm{FEV}_{1}\right)$ based on the Copenhagen City Heart Study ${ }^{2}$ are biased. We disagree, and rather believe that our study of the general population is prone to less bias than case-control or family based studies.

Dr Seersholm argues that, because we genotyped study participants after measurement of $\mathrm{FEV}_{1}$ in 1976-8, 1981-4, and 1991-4, our results are biased. ${ }^{1}$ Certainly, if conventional risk factors are measured after development of disease, the disease might be the cause of the risk factor rather than vice versa. However, an $\alpha_{1}$-antitrypsin MZ genotype in a newborn does not change into a $\mathrm{ZZ}$ genotype by age. Therefore, the Pi MZ genotype preceded $\mathrm{FEV}_{1}$ outcomes in our study, even though genotypes were determined after $\mathrm{FEV}_{1}$ measurements. Using identical logic, the genotype preceded outcomes in a similar manner in other previous studies..$^{3-6}$

Selection bias could potentially be a reason for discrepancies between studies on Pi MZ and COPD. ${ }^{17}$ In our study, where genotype distribution was in Hardy-Weinberg equilibrium, we found no evidence for selection against any $\alpha_{1}$-antitrypsin genotype. ${ }^{28}$ Therefore, as also pointed out by $\mathrm{Dr}$ Seersholm, ${ }^{1}$ selection bias is more likely in case-control and family based studies than in cohort studies of the general population.

M Dahl, B G Nordestgaard

Department of Clinical Biochemistry, Herlev University Hospital, Copenhagen, Denmark; mdah@partners.org

\section{References}

1 Seersholm N. Pi MZ and COPD: will we ever know? Thorax 2004;59:823-5.

2 Dahl M, Tybjærg-Hansen A, Lange $P$, et al Change in lung function and morbidity from chronic obstructive pulmonary disease in alphalantitrypsin $M Z$ heterozygotes. A longitudinal study of the general population. Ann Intern Med 2002; 136:270-9

3 Juul K, Tybjærg-Hansen A, Steffensen R, et al. Factor $V$ leiden: The Copenhagen City Heart Study and 2 meta-analyses. Blood 2002; 100:3-10

4 Bojesen SE, Tybjærg-Hansen A, Nordestgaard BG. Integrin beta3Leu33Pro homozygosity and risk of cancer. J Natl Cancer Inst 2003;95:1150-7.

5 Dahl M, Tybjærg-Hansen A, Schnohr P, et al. A population based study of morbidity and mortality in mannose-binding lectin deficiency. J Exp Med 2004; 199:1391-9.

6 Wadsworth MEJ, Vinall LE, Jones AL, et al. Alpha-1-antitrypsin as a risk factor for infant and adult respiratory outcomes in a national birth cohort. Am J Respir Cell Mol Biol 2004;31:559-64.

7 Hersh CP, Dahl M, Ly CS, et al. Chronic obstructive pulmonary disease in alphalantitrypsin PI MZ heterozygotes: a meta-analysis. Thorax 2004;59:843-9.

8 Dahl M, Tybjærg-Hansen A, Sillesen $\mathrm{H}$, et al. Blood pressure, risk of ischemic cerebrovascular and ischemic heart disease, and longevity in alphal-antitrypsin deficiency: the Copenhagen City Heart Study. Circulation 2003;107:747-52.

\section{Authors' reply}

Drs Dahl and Nordestgaard argue against selection bias if genotyping is performed after lung function tests because a newborn with a Pi MZ genotype does not change to $\mathrm{Pi} \mathrm{ZZ}$ later in life. The latter is obviously true and not the issue. The reason for possible selection bias is that some people may fail to have genotype performed due to a characteristic of the lung function tests under study, and this may affect the result of a longitudinal study.

If we assume that subjects with a Pi MZ genotype have a very fast decline in forced expiratory volume in 1 second $\left(\mathrm{FEV}_{1}\right)$ with premature death, a number of them may have attended the first examinations but did not live long enough to attend the last visit with genotyping. They would not therefore be included in the analysis of $\mathrm{FEV}_{1}$ decline and the result would be an underestimate of the decline in $\mathrm{FEV}_{1}$ with the possible conclusion 
that Pi MZ is not a risk factor for lung disease. This is usually called a "survivor effect".

The opposite may also be true. Suppose there is a reverse relationship between pulmonary function and compliance with study visits-that is, subjects with a normal $\mathrm{FEV}_{1}$, normal $\mathrm{FEV}_{1}$ decline, and no lung symptoms may not attend the last visit because they feel well. This would tend to exaggerate any increased decline in $\mathrm{FEV}_{1}$ and the conclusion could be that Pi MZ is an important risk factor for lung disease.

These are just two of many examples of possible biases. They show that, even if the risk factor (Pi MZ) is present from birth, it is vital to postpone the collection of tests for analysis after genotyping has been performed.

N Seersholm

Pulmonary Department Y, Gentofte Hospital, Niels Andersens Vej 65, DK-2900 Hellerup. Denmark;
seersholm@dadlnet.dk

\section{Exhaled breath condensate in chronic cough}

We read with interest the recent article by Niimi et al reporting low levels of exhaled breath condensate (EBC) $\mathrm{pH}$ in patients with chronic cough. ${ }^{1}$ We and others have described low EBC $\mathrm{pH}$ in association with airway inflammation in allergic asthma, cystic fibrosis, and chronic obstructive pulmonary disease. ${ }^{2-4}$ In these studies there is a relatively close association between inflammation and low $\mathrm{pH}$ which is shown by the further fall in $\mathrm{pH}$ during exacerbations. ${ }^{2}$ However, in nonasthmatic chronic cough, while there is a low grade inflammation present in some subjects, this is much less than would be required to invoke inflammation as the major cause of airway acidification.

It is unclear from the description of the assessment protocol how patients were allotted their individual diagnostic categories. A positive methacholine challenge test is not infrequently found in patients with reflux ${ }^{5}$ and, even in classical asthma, reflux is a common phenomenon. ${ }^{6}$ We suggest that there has been a significant underdiagnosis of reflux disease in this cohort because of the lack of a structured history, the non-uniform application of investigations, and the failure to perform full oesophageal assessment, particularly manometry. We have shown that, when oesophageal manometry is not performed, a significant number of patients with reflux cough will be missed. ${ }^{7}$ Proton pump inhibitors at conventional doses only temporarily increase the $\mathrm{pH}$ of gastric reflux and do not prevent reflux per se and, unsurprisingly, only improve symptoms in a proportion of patients with reflux cough. A failure of cough to improve with proton pump inhibitors does not therefore adequately rule out reflux cough.

The simplest explanation for the low airway $\mathrm{pH}$ observed by Niimi et al would be that a large proportion of the subjects had laryngopharyngeal reflux. This would also explain the otherwise surprising finding of similar EBC $\mathrm{pH}$ across the authors' diagnostic categories.

A Morice, C F Everett, S A Mulrennan

Academic Department of Medicine, Castle Hill Hospital, Cottingham, East Yorkshire HU16 5JQ, UK; a.h.morice@hull.ac.uk

\section{References}

1 Niimi A, Nguyen LT, Usmani O, et al. Reduced pH and chloride levels in exhaled breath condensate of patients with chronic cough. Thorax 2004;59:608-12.

2 Ojoo JC, Mulrennan S, Kastelik JA, et al. Exhaled breath condensate $\mathrm{pH}$ and exhaled nitric oxide in allergic asthma and in cystic fibrosis. Thorax 2005;60:22-6.

3 Kostikas K, Papatheodorou G, Ganas K, et al. pH in expired breath condensate of patients with inflammatory airway diseases. Am J Respir Crit Care Med 2002;165:1364-70.

4 Tate S, MacGregor G, Davis M, et al. Airways in cystic fibrosis are acidified: detection by exhaled breath condensate. Thorax 2002;57:926-9.

5 Bagnato GF, Gulli S, Giacobbe O, et al. Bronchial hyperresponsiveness in subjects with gastroesophageal reflux. Respiration 2000;67:507-9.

6 Vincent DAM, Leport J, et al. Gastro-oesophageal reflux prevalence and relationship with bronchial reactivity in asthma. Eur Respir $J$ 1997:10:2255-9.

7 Kastelik JA, Redington AE, Aziz I, et al. Abnormal oesophageal motility in patients with chronic cough. Thorax 2003;58:699-702.

\section{Authors' reply}

We thank Professor Morice and his colleagues for their interest in our paper. The main issue they raise concerns the possibility that we may have missed gastro-oesophageal disorders such as reflux and dysmotility in our cohort of patients with chronic cough. In our assessment protocol we state that we used oesophageal $\mathrm{pH}$ measurements in most patients (32 of 50 ), together with a trial of proton pump inhibitors. We are pleased to read from Professor Morice that proton pump inhibitors "only improve symptoms in a proportion of patients with reflux cough", when they reported previously a very excellent $82 \%$ therapeutic response in this group treated with "proton pump inhibitors, alginates and conventional advice regarding diet and posture". ${ }^{1}$ We agree entirely that proton pump inhibitors are not very efficacious in reflux cough. We have not performed oesophageal manometry and are aware of Professor Morice's interesting observations. They also report that patients with abnormal oesophageal manometry respond to proton pump inhibition, and therefore we would have picked up such patients with a trial of proton pump inhibitor treatment. However, the direct link between oesophageal dysmotility and chronic cough still remains to be established.

We do not believe we have missed reflux as an associated cause of the cough and therefore do not agree with the explanation that the reduced exhaled breath condensate $\mathrm{pH}$ is a reflection of laryngopharyngeal reflux throughout the diagnostic categories. Rather, this is likely to be related to the chronic inflammatory and remodelling process that is present in the submucosa of chronic cough patients, associated with both asthma and non-asthmatic causes.. ${ }^{2-4}$ We must emphasise that we are assuming that exhaled breath condensate is a reflection of the epithelial surface liquid, which needs to be confirmed.

K F Chung, A Niimi

Department of Thoracic Medicine, National Heart and Lung Institute, Imperial College, Dovehouse Street, London SW3 6LY, UK; f.chung@imperial.ac.uk

\section{References}

1 Kastelik JA, Redington AE, Aziz I, et al. Abnormal oesophageal motility in patients with chronic cough. Thorax 2003;58:699-702.

2 Niimi A, Matsumoto $H$, Minakuchi $M$, et al. Airway remodelling in cough-variant asthma. Lancet 2000;356:564-5.

3 Boulet LP, Milot J, Boutet M, et al. Airway inflammation in non-asthmatic subjects with chronic cough. Am J Respir Crit Care Med 1994; 149:482-9.

4 Niimi A, Cosio B, Oates T, et al. Airway inflammation and remodelling in non-asthmatic patients with chronic cough: comparison with asthmatics. Am J Respir Crit Care Med 2003; 167:A353.

\section{Bilateral non-traumatic second rib fracture after bilateral first rib resection for TOS}

Thoracic outlet syndrome (TOS), which is caused by osseous and soft tissue abnormalities and presents as tingling, paraesthesia, and weakness of the extremity, is a controversial subject. Surgical treatment for TOS is seen as the last resort and involves resection of the first rib and scalenotomy and leads to an overall improvement of $70 \%$ over a period of 5 years. ${ }^{1}$ The most common postoperative complications are pneumothorax, injury to the subclavian artery and vein, or brachial plexus and long thoracic nerve. ${ }^{2}$ Second rib fracture as a complication after surgery for TOS has not previously been described.

A 54 year old woman had been symptomatic with bilateral constant numbness, tingling, paraesthesia, and weakness exacerbated by sports and exercises for well over 10 years. Numerous attempts at conservative treatment had failed. She also had bilateral omarthrosis which had been treated by previous acromioclavicular joint resection and subacromial decompression. Nevertheless, the symptoms persisted and increased in both ulnar innervated segments of the arm. The hyperabduction test (Wright) was positive on both sides. In conjunction with her other symptoms, a diagnosis of bilateral neurovascular TOS was established and the patient underwent transaxillary first rib resection on the right side. Any injury to the second rib during surgery could be ruled out. Her recovery was uneventful and both pain and numbness were greatly improved.

Two months later transaxillary first rib resection was performed on the left side. Again the symptoms improved. Three weeks after this operation the patient felt a sudden crack and tenderness in her left shoulder girdle with no previous minor or major trauma. Radiographs showed an anterolateral left second rib fracture. Two months later the patient developed sudden tenderness in her right shoulder, again with no previous trauma, and a posterolateral second rib fracture was diagnosed by radiography. An osteodensitometric study showed only a slightly deficient calcium intake of estimated $1150 \mathrm{mg}$ instead of $1500 \mathrm{mg}$ per day. T-scores were within the normal range and no diagnosis of osteoporosis could be established. A technetium-99m bone scan and a SPECT showed increased pathological activity in both second ribs consistent with the fractures, but no other abnormalities (fig l). The patient was treated conservatively and recovered very well; she has had no further problems. 


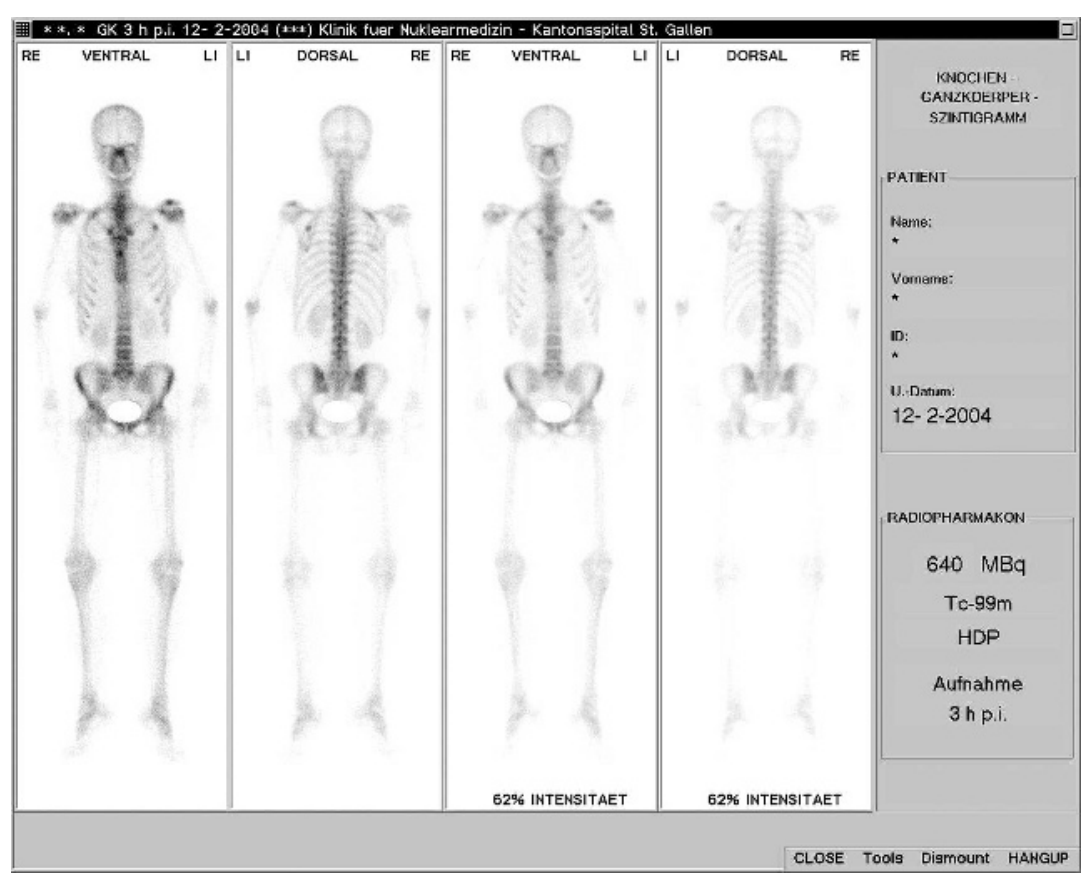

Figure 1 Technetium-99m bone scan of patient.

Fractures of the first rib are very rare and bilateral fractures are even more uncommon. ${ }^{3-9}$ Bilateral fracture of the second rib has not been described previously. After first rib resection the second rib becomes the most cranial rib and thus takes the place of the former first rib. Second rib fracture after first rib resection can therefore be compared with first rib fractures in patients who have not undergone first rib resection. Several theories on the aetiology of first rib fractures exist. ${ }^{67}$ Traumatic fractures usually involve not only the first rib but also the clavicle or scapula. Considerable force is required to fracture the first rib since it is protected very well by soft tissue and the clavicle and scapula. Nontraumatic fractures occur without adequate trauma and are regarded as stress fractures and usually can be found in the weakest portion of the rib. ${ }^{3-8}$ Fractures present with upper chest pain and tenderness. ${ }^{3}$ Some authors have doubted the existence of this type of fracture and classify it as a congenital anomaly. ${ }^{10}$

Most authors explain the stress fracture by the anatomy of the first rib. ${ }^{3-8}$ The rib is broad and flat and weakened by the groove where the subclavian artery crosses it. The scalene muscles produce a bending force in the rib causing it to fracture. This theory has been questioned since it would mean that all fractures would occur at the same location. ${ }^{3}$ After first rib resection for TOS the second rib takes the place of the first rib and faces the same stress as the former first rib. The second rib is thinner and not as wide as the first rib, leaving it even more vulnerable to stress. This can explain the relatively short time between first rib resection and fracture of the second rib on the left side in our patient. This left the rib with insufficient time to adapt to the increased force after first rib resection. The clavicle may exert pressure on the second rib, particularly when carrying heavy loads. Our patient denied vigorous exercise before the fracture. The fracture of the right second rib may be explained by increased stress due to impaired movement of the left shoulder. Furthermore, scar remodelling around the rib may have impaired motion leaving the rib prone to fracture. The two fractures occurred in different parts of the rib. We conclude that second rib. Also, no muscle insertion on the rib is responsible for the fracture. A pathological fracture resulting from bone metastases was ruled out and there was no osteoporosis which would have made the bones more prone to trauma. We classify the fractures as spontaneous non-traumatic fractures in an otherwise healthy patient.

Spontaneous non-traumatic fractures of the first and second ribs remain a controversial topic. The fractures presented with pain and tenderness. Upper chest pain is the only symptom in such patients, and a second rib fracture should be considered in patients who develop chest pain after first rib resection.

M G Jakubietz, R G Jakubietz, J G Gruenert Kantonsspital St Gallen, Handchirurgie, St Gallen, Switzerland

$M$ Langer

Universitätsklinikum Münster, Unfall-, Handchirurgie, Münster, Germany

Correspondence to: $\operatorname{Dr} M$ G Jakubietz, Kantonsspital St Gallen, Handchirurgie, St Gallen, Switzerland 9007; Michael.jakubietz@kssg.ch

\section{References}

1 Atasoy E. Thoracic outlet compression syndrome. Orthop Clin North Am 1996;27:265-303.

2 Leffert RD. Complications of surgery for thoracic outlet syndrome. Hand Clin 2004;20:91-8.

3 Tsukada A, Uchiyama S, Toriumi $\mathrm{H}$, et al. Nontraumatic bilateral first rib fractures. Acta Orthop Belg 1998;64:406-8.

4 Leung $\mathbf{H}$, Stirling A. Stress fracture of the first rib without associated injuries. Injury $1991 ; 22: 483-4$.

5 Dwivedi S, Varma A. Bilateral fracture of the first ribs. J Trauma 1983:538-9. there is no point of least resistance in the
6 Lorentzen J, Movin M. Fracture of the first rib. Acta Orthop Scand 1976;47:632-4.

7 Frangakis E. Fractures of the first rib. Acta Orthop Scand 1967;38:193-8.

8 Breslin FJ. Fracture of the first rib unassociated with fractures of other ribs. Am J Surg 1937;38:384-9.

9 Jenkins S. Spontaneous fractures of both first ribs. $J$ Bone Joint Surg 1952;34:9-13.

10 Bowie ER, Jacobsen HG. Anomalous development of the first rib simulating isolated fracture. Am J Roentgenol 1945;53:384-9.

\section{BOOK REVIEW}

\section{Chronic Obstructive Pulmonary Disease: Second Edition}

P M A Calverley, W MacNee, N B Pride, P M Rennard, Editors. London: Arnold, 2003, £110.00. ISBN 0340807180

If I want to find the latest research papers quickly, the internet is the place to go. For advice on management there is no shortage of reputable guidelines. So what use is the old style textbook? The editors of the second edition of Chronic Obstructive Pulmonary Disease touch on this question as they introduce their own book and suggest that what they offer is time and depth. A textbook allows consideration of all aspects of a disease-not just the latest trials in COPD but the development and pathophysiology of the condition-and time to address the full background to active research topics even if the very latest advances cannot be incorporated. Contributors to a textbook have the opportunity to present a detailed exposition of a topic in a way that few readers could manage themselves via a trawl of the internet.

So has this opportunity been taken in Chronic Obstructive Pulmonary Disease? Overall, I think it has. No textbook is meant to be read from cover to cover and I haven't tried, but I did start at the beginning and, if thoughtful consideration is the hallmark of a textbook, then the opening chapter on definitions certainly sets the correct tone. Anyone who weaves Alice in Wonderland and Karl Popper into the first few pages of a medical book is doing rather more than going through the motions. This is a nice start, but perhaps the real test of any textbook is how well it explains the topics on which the reader is ignorant. I found myself worryingly spoilt for choice but decided to start with the chapters on "Oxidative Stress" and "Airway Repair", both of which are written by members of the editorial team. The styles are different but I learned from both. The chapter on "Oxidative Stress" is certainly detailed but worth the effort, and the briefer chapter on "Airway Repair" provided an extremely useful summary for an uninitiated person like myself. Several other chapters also brought rewards, not least those on "Lung Mechanics" and "Exercise" and the well written summary of "Pulmonary Rehabilitation". The smaller number of chapters whose subject matter I like to think I know well inevitably seemed a little less informative, but there are none anywhere near poor enough to be highlighted here. There is far more to applaud than to be disappointed with. 
No-one will believe a review free of complaints, so I should list some. I think the editors might consider the balance of the chapters. Should there be seven pages on " $\alpha_{1}$ Antitrypsin" when the whole "Pathology" chapter only gets the same? Or just nine pages on "Inflammation" when "Oxidative Stress" contains 20? There are also a few omissions. Despite the explanation in the Preface, I think it would be nice to have a chapter summarising the role of cigarette smoking and the mechanisms underlying this (a chapter on "Smoking Cessation" compensates in part). A good chapter on "Oxygen Therapy" offers little about short burst oxygen, and I struggled to find anything on the current debate regarding the role of inhaled steroids in preventing a decline in $\mathrm{FEV}_{1}$ (it's actually under the slightly misleading subheading "Short-term Treatment with Inhaled Corticosteroids").

But these are minor quibbles. The package as a whole is of high quality and pitched at a level which will be appreciated by respiratory trainees, consultants, and the interested general physician.
A walk through the average medical school or hospital library suggests that there is still an appetite for textbook learning, and those wishing to know more about COPD will be well served by this title.

B G Higgins

Freeman Hospital, Newcastle upon Tyne NE7 7DN, UK; b.g.higgins@nd.ac.uk

\section{CORRECTION}

doi: 10.1136/thx.2004.024604corr l

\section{Asthma exacerbation in children immediately following stressful life events}

In the paper entitled "Asthma exacerbations in children immediately following stressful life events: a Cox's hierarchical regression" by $\mathrm{S}$ Sandberg et al which appeared in the December issue of Thorax (2004; 59:1046-51), some of the statistics have been incorrectly presented.

In the Results section of the abstract on page 1046, the first sentence should read: "An immediate effect evident within the first 2 days following a severely negative life event increased the risk of a new asthma attack by a factor of $4.69,95 \%$ confidence interval 2.33 to $9.44(\mathrm{p}<0.001)^{\prime \prime}$. The third sentence should read: "In addition to the immediate effect, an increased risk of 1.81 (95\% confidence interval 1.24 to 2.65 ) was found 5-7 weeks after a severe event $(\mathrm{p}=0.002)^{\prime \prime}$.

On page 1049 the third paragraph should read: "The effect of a severely negative life event was as follows. The immediate effect corresponding to 1-2 days after the event increased the risk of a new asthma exacerbation by a factor of 4.69 (95\% confidence interval 2.33 to 9.44 ) which was statistically significant $(\mathrm{p}<0.001)$, whereas the effect for days 3-10 after the event was not statistically significant $(p=0.5)$. The risk of an asthma attack varied considerably between children; the frailty term was highly significant $(\mathrm{p}<0.001) . "$ 